\begin{tabular}{|c|c|}
\hline Title & Identification of novel sesterterpenes by genome mining of phytopathogenic fungi Phoma and Colletotrichum sp. \\
\hline Author(s) & $\begin{array}{l}\text { Gao, Lei; Narita, Koji; Ozaki, Taro; Kumakura, Naoyoshi; Gan, Pamela; Minami, A tsushi; Liu, Chengwei; Lei, } \\
\text { Xiaoguang; Shirasu, Ken; Oikawa, Hideaki }\end{array}$ \\
\hline Citation & $\begin{array}{l}\text { Tetrahedron Letters, 59(12), } 1136-1139 \\
\text { https://doi.org/10.1016/.tetlet.2018.02.022 }\end{array}$ \\
\hline Issue Date & 2018-03-21 \\
\hline Doc URL & http:/hdl.handle.net/2115/76980 \\
\hline Rights & (2018. This manuscript version is made avail able under the CC-BY-NC-ND 4.0 license \\
\hline Rights(URL) & http://creativecommons.org/icenses/by-nc-nd/4.0/ \\
\hline Type & article (author version) \\
\hline File Information & manuscript_180207-v2_1.pdf \\
\hline
\end{tabular}

Instructions for use 


\section{Graphical Abstract}

To create your abstract, type over the instructions in the template box below.

Fonts or abstract dimensions should not be changed or altered.

Identification of novel sesterterpenes by genome mining of phytopathogenic fungi

Leave this area blank for abstract info.

Phoma and Colletotrichum sp.

Lei Gao, Koji Narita, Taro Ozaki, Naoyoshi Kumakura, Pamela Gan, Atsushi Minami, Chengwei Liu, Xiaoguang Lei, Ken Shirasu, and Hideaki Oikawa
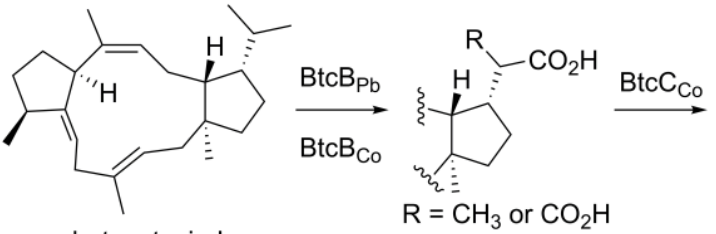

betaestacin I

$\mathrm{R}=\mathrm{CH}_{3}$ or $\mathrm{CO}_{2} \mathrm{H}$

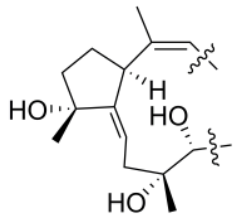

betaestacin $\mathrm{Va}$ 
Tetrahedron Letters

journal homepage: www.elsevier.com

\title{
Identification of novel sesterterpenes by genome mining of phytopathogenic fungi Phoma and Colletotrichum sp.
}

\author{
Lei $\mathrm{Gao}^{\mathrm{a}, \mathrm{b}}$, Koji Narita ${ }^{\mathrm{a}}$, Taro Ozaki ${ }^{\mathrm{a},}$, Naoyoshi Kumakura ${ }^{\mathrm{c}}$, Pamela Gan ${ }^{\mathrm{c}}$, Atsushi Minami ${ }^{\mathrm{a}}$, Chengwei \\ Liu $^{\mathrm{a}}$, Xiaoguang Lei ${ }^{\mathrm{b}}$, Ken Shirasu ${ }^{\mathrm{c}}$, and Hideaki Oikawa ${ }^{\mathrm{a}, *}$ \\ ${ }^{a}$ Division of Chemistry, Graduate School of Science, Hokkaido Universiy, Sapporo 060-0810, Japan \\ ${ }^{b}$ College of Chemistry and Molecular Engineering, Peking University, Haidan District, Beijing 100871, China \\ ${ }^{C}$ Plant Immunity Research Group, RIKEN Center for Sustainable Resource Science, Kanagawa 230-0045, Japan
}

\section{ARTICLE INFO}

\author{
ABSTRACT
}

\section{Article history:}

Received

Received in revised form

Accepted

Available online

\section{Keywords}

Keyword_1 sesterterpene synthase

Keyword_2 genome mining

Keyword_3 natural product biosynthesis

Keyword_4 phytopathogen

Keyword_5 heterologous expression
Two homologous gene clusters for the biosynthesis of sesterterpenes betaestacins were identified from two phytopathogens, Phoma betae and Colletotrichum orbiculare. Heterologous expression of identified oxidation enzymes with previously-characterized PbTS1 (BtcA $\mathrm{Pb}_{\mathrm{Pb}}$ resulted in the production of seven novel sesterterpenes. Although both strains possessed homologous enzymes, oxidation state of corresponding products were different from each other, suggesting that structural diversification of sesterterpene skeletons might be achieved by these homologous enzymes with different functions.

2009 Elsevier Ltd. All rights reserved.

\section{Introduction}

Bifunctional terpene synthases (BFTSs) are the multifunctional enzymes composed of two distinct domains, an $\mathrm{N}$-terminal terpene synthase (TS) domain and a C-terminal prenyltransferase domain. The first example of this enzyme class is a fusicoccadiene synthase (PaFS), which was isolated from Phomopsis amygdali ${ }^{1}$. Interestingly, a second BFTS, a phomopsene synthase (PaPS), was identified in this strain as well ${ }^{2}$. Previously, we employed the $A$. oryzae expression system to characterize cryptic terpene synthases in fungal genomes and identified the first example of a sesterterpene synthase (AcOS) that catalyzed geranylfarnesyl diphosphate (GFPP) synthesis followed by its cyclization to yield ophiobolin $\mathrm{F}^{3}$. This finding showed that BFTSs synthesize not only diterpenes but also the C25 sesterterpenes. After this finding, genome mining has become a standard method for the identification of novel sesterterpenes as in the case of sesterfisherol synthase (NfSS) ${ }^{4}$. To date, more than 10 BFTSs have been characterized by several research groups ${ }^{5-10}$. In addition, a robust $A$. oryzae expression system also allowed us to perform co-expression of modification enzymes with BFTS, which functionalize sesterterpene skeletons ${ }^{4,11}$. Herein, we report the identification of seven novel sesterterpenes by genome mining of BFTS against two phytopathogens, Phoma betae and Colletotrichum orbiculare.

\section{Results and discussion}

We have proposed that the initial cyclization modes of BFTSs were closely correlated with the amino acid sequences of the TS domains ${ }^{4}$. For example, BFTSs classified into Clade A catalyze the A-ring formation at the $\mathrm{C} 1-\mathrm{C} 15 / \mathrm{C} 14-\mathrm{C} 18$ position of GFPP to give a 5-15 ring system. Recently, focused expression of Clade A BFTSs enabled us to characterize four sesterterpene synthases, BmTS1, BmTS2, BmTS3, and PbTS1 $\left(\mathrm{BtcA}_{\mathrm{Pb}}\right)$, that produce the structurally-related sesterterpenes, $\mathrm{Bm} 1, \mathrm{Bm} 2, \mathrm{Bm} 3$, and $\mathrm{Pb} 1$ (1, named betaestacin I in this study, Scheme 1). These products were proposed to be derived from the diastereomeric cationic intermediates in the NfSS reaction based on the determination of their absolute configurations and DFT calculations ${ }^{12}$. Because a $b t c A_{P b}$ gene was clustered with the three genes encoding oxidation enzymes (two P450s, $\mathrm{BtcB}_{\mathrm{Pb}}$ and $\mathrm{BtcC}_{\mathrm{Pb}}$, and one $\alpha-$ ketoglutarate-dependent dioxygenase $\mathrm{BtcD}_{\mathrm{Pb}}$ ), we expected that heterologous expression of these enzymes could result in production of oxidized derivative(s) of the hydrocarbon 1. On the other hand, we employed independent study for genome mining of the uncharacterized gene clusters expressed during the infection by Colletotrichum orbiculare. Based on transcriptomic analysis of this strain, we selected a cluster that consisted of another Clade A BFTS, BtcA $\mathrm{C}_{\mathrm{Co}}$. Heterologous expression of this enzyme resulted in the production of the same hydrocarbon 1 (Figure S1 \& S2), despite its relatively low homology with Btc $_{\mathrm{Pb}}$ (39\% amino acid identity). $b t c A_{C o}$ was also clustered with $b t c B_{P b}$ and $b t c C_{P b}$ homologs (36-38\% sequence identity), suggesting that both gene clusters could give the same product(s). Therefore, $\mathrm{BtcB}_{\mathrm{Pb}}, \mathrm{BtcC}_{\mathrm{Pb}}$, and $\mathrm{BtcD}_{\mathrm{Pb}}$ were initially expressed in $A O-b t c A_{P b}$, which produced $\mathbf{1}^{12}$.

$\mathrm{P} 450$ genes $b t c B_{P b}$ and $b t c C_{P b}$ were cloned into the plasmid pUSA2 to construct pUSA2- $b t c B_{P b}$ and pUSA2- $b t c B_{P b} C_{P b}$, while $b t c D_{P b}$ was cloned into the plasmid pAdeA2 to construct 
A

Phoma betae PS-13

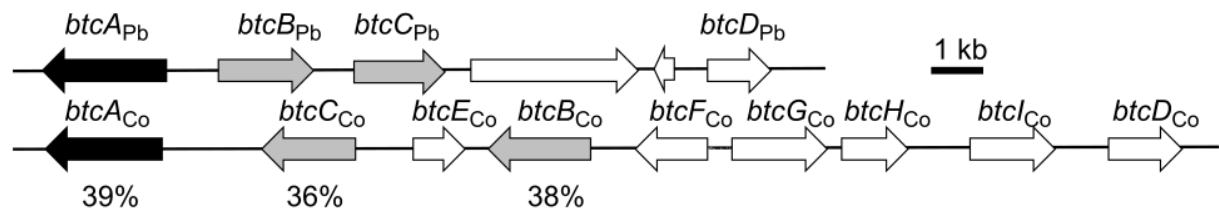

B

Colletotrichum orbiculare MAFF 24042

betaestacin I (1)

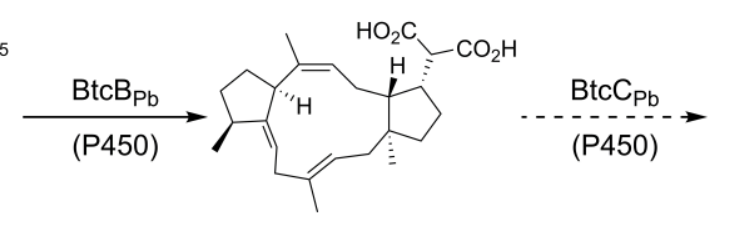

betaestacin II (2)

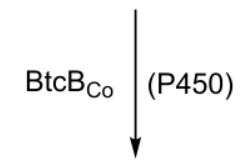

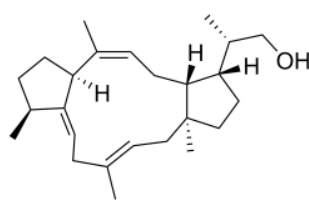

betaestacin III (3)

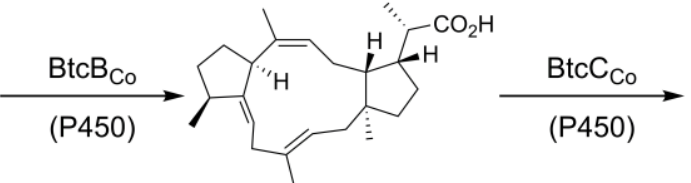

betaestacin IV (4)

no further
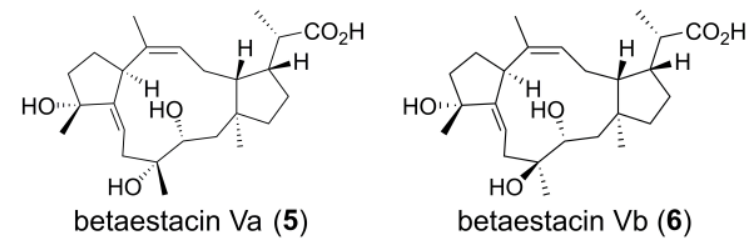

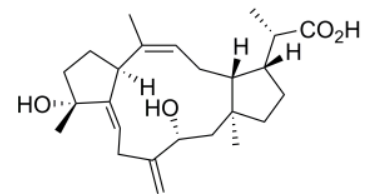

betaestacin Vc (7)

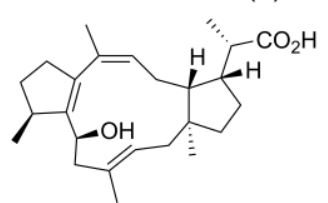

betaestacin $\mathrm{VI}(\mathbf{8})$

Scheme 1 A) Biosynthetic gene clusters for betaestacins in P. betae and $C$. orbiculare. B) Proposed biosynthetic pathway of sesterterpenes isolated in this study.

pAdeA2-btc $D_{P b}$. Subsequently, resulting plasmids were intr oduced into the transformant AO-btcA $A_{P b}$. The metabolite profile of the $A O-b t c A_{P b} B_{P b}$ cultured on a solid medium was examined, and a new metabolite 2 was readily identified (Figure 1A). Based on HR-ESI-MS analysis, the molecular formula of $\mathbf{2}$ was determined to be $\mathrm{C}_{25} \mathrm{H}_{35} \mathrm{O}_{4}\left(\mathrm{~m} / \mathrm{z} 399.2504[\mathrm{M}-\mathrm{H}]^{-}\right)$. In the ${ }^{1} \mathrm{H}$ NMR spectrum of 2, a pair of characteristic doublet signals (H24 and $\mathrm{H} 25$ ) of isopropyl group was absent. Instead, new peaks with $\delta_{\mathrm{c}} 174.1$ and 174.0 appeared in ${ }^{13} \mathrm{C} \mathrm{NMR}$, indicating presence of the geminal diacid moiety. This speculation was further confirmed by HMBC correlations between C24/C25 and both H19 and H18 (Figure S3). Hereafter, we named this compound betaestacin II (2). Other related metabolites are noted in similar way. Isolation of $\mathbf{2}$ indicated that $\mathrm{BtcB}_{\mathrm{Pb}}$ is unequivocally responsible for the six-step oxidation of 1 . Because AO$b t c A_{P b} B_{P b} C_{P b}$ (Figure 1A) and $\mathrm{AO}-b t c A_{P b} B_{P b} C_{P b} D_{P b}$ (data not shown) did not produce further oxidized metabolites, $\mathrm{BtcC}_{\mathrm{Pb}}$ and $\mathrm{BtcD}_{\mathrm{Pb}}$ were likely inactive in our current experimental conditions. In the case of the biosynthesis of ophiobolins, P450 derived from the producer strain catalyzed the expected oxidation, while a homologous enzyme from the cryptic gene cluster catalyzed unusual oxidations ${ }^{11}$. Considering the possibility that enzymes encoded in the cryptic $b t c X_{\mathrm{Pb}}$ gene cluster lost their original function, we next examined the heterologous expression of corresponding oxidation enzymes from the gene cluster derived from $C$. orbiculare.

The plasmids pUSA2- $b t c B_{\mathrm{Co}}$ and pUSA2- $b t c B_{\mathrm{Co}} C_{\mathrm{Co}}$, constructed by stepwise cloning of $b t c B_{\mathrm{Co}}$ and $b t c C_{\mathrm{Co}}$ into pUSA2, were introduced to the transformant $\mathrm{AO}-b t c A_{\mathrm{Pb}}$ that synthesized the same hydrocarbon 1 to yield $\mathrm{AO}-b t c A_{P b} B_{C o}$ and $\mathrm{AO}-$ $b t c A_{P b} B_{C o} C_{C o}$. In the LC-MS analysis of AO-btc $A_{P b} B_{C o} C_{C o}$ extracts, at least five metabolites were detected (compounds 4 8) (Figure 1B). Their molecular formulae were determined to be $\mathrm{C}_{25} \mathrm{H}_{37} \mathrm{O}_{2}, \quad \mathrm{C}_{25} \mathrm{H}_{39} \mathrm{O}_{5}, \quad \mathrm{C}_{25} \mathrm{H}_{39} \mathrm{O}_{5}, \quad \mathrm{C}_{25} \mathrm{H}_{37} \mathrm{O}_{4}, \quad$ and $\mathrm{C}_{25} \mathrm{H}_{39} \mathrm{O}_{3}$, respectively, by HR-ESI-MS analysis, suggesting that these compounds were the oxidized derivatives of $\mathbf{1}$ and shared the same carbon skeleton. Therefore, the structural analyses of these compounds were mainly performed by comparing NMR spectra of these compounds with those of $\mathbf{1}$ (Table S5).

At first, we determined the structure of the major metabolite 4 (betaestacin IV). Doublet methyl signal (H25) of the isopropyl group in 1 was absent in its ${ }^{1} \mathrm{H}$ NMR spectra while a signal with $\delta_{c} 182.2$ appeared in ${ }^{13} \mathrm{C}$ NMR, suggesting the presence of one carboxyl group in 4. HMBC correlations between $\mathrm{C} 25$ and both H19 and H24 confirmed the presence of an oxidized moiety derived from the isopropyl group (Scheme 1). Production of 4 in AO-btc $A_{P b} B_{C o}$ (Figure 1B) revealed that $\mathrm{BtcB}_{\mathrm{Co}}$ was solely responsible for the three-step oxidation of $\mathbf{1}$. From the NOE correlations between $\mathrm{H} 19-\mathrm{H} 23$ and $\mathrm{H} 17-\mathrm{H} 24$, a newly formed chiral center was determined to be 195 (Figure S3). During isolation of the carboxylic acid $\mathbf{4}$ by large-scale fermentation a minor component $\mathbf{3}$ was also isolated. Its HR-ESI-MS analysis showed a signal with $\mathrm{m} / z 357.3178\left([\mathrm{M}+\mathrm{H}]^{+}\right.$, calcd. 357.3132 for $\mathrm{C}_{25} \mathrm{H}_{41} \mathrm{O}$ ). Based on its molecular formula, 3 was assumed to be a hydroxylated derivative of $\mathbf{1}$. Methylation of the carboxylic acid 4 and its subsequent reduction by $\mathrm{LiAlH}_{4}$ gave 3 (Figure S4), indicating that this compound was a $\mathrm{C} 25$-hydroxylated derivative of 1 .

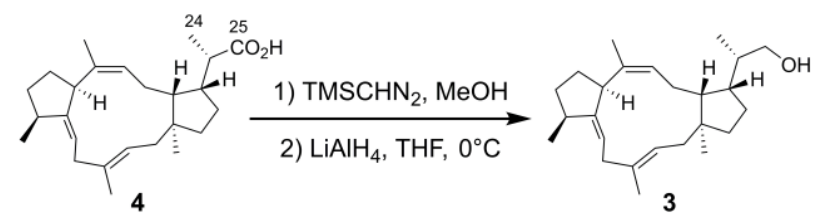

Compounds 5 and $\mathbf{6}$ (betaestacin $\mathrm{Va}$ and $\mathrm{Vb}$ ) had the same molecular formulae, which had three more oxygens and two more hydrogens compared to $\mathbf{4}$, indicating that these were the oxidation products of 4 . Their ${ }^{1} \mathrm{H}$ and ${ }^{13} \mathrm{C}$ NMR spectral data (Table S5) showed that C2-C3 double bond and allylic C7-proton signals were missing while three oxygenated carbon signals were observed in 72-79 ppm, suggesting that these compounds were 


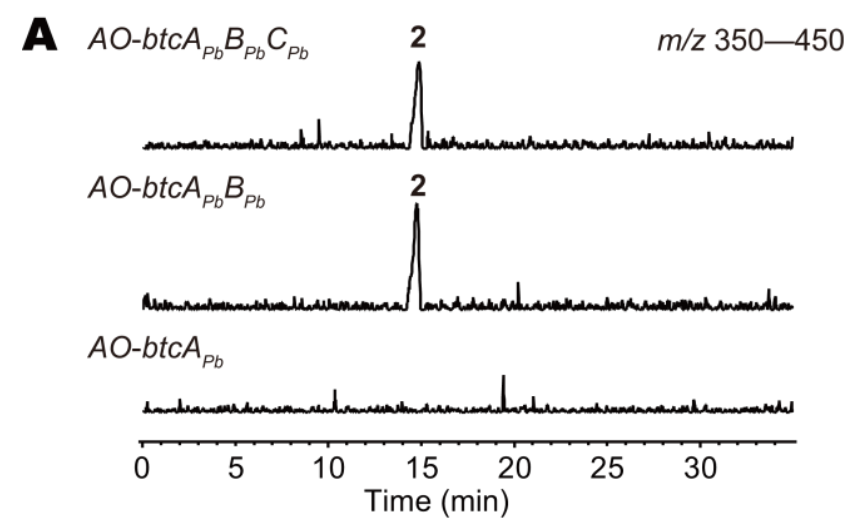

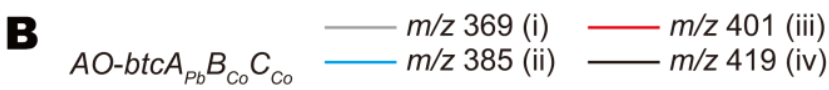
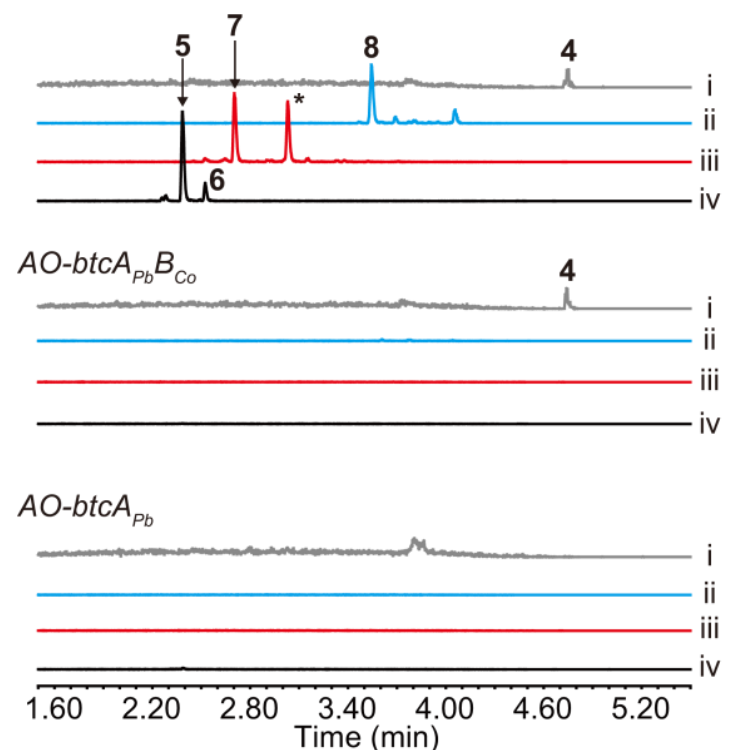

Figure 1, HPLC-MS analysis of the metabolites extracted from (A) AO$b t c A_{\mathrm{Pb}}, A O-b t c A_{P b} B_{\mathrm{Pb}}$, and $A O-b t c A_{P b} B_{P b} C_{\mathrm{Pb}}$. Chromatograms were extracted at $m / z, 350-450$. (B) $A O-b t c A_{\mathrm{Pb}}, A O-b t c A_{P b} B_{C o}$, and $A O$ $b t c A_{P b} B_{C o} C_{C o}$. Chromatograms were extracted at $\mathrm{m} / z 369$ (for 4), $\mathrm{m} / z 385$ (8), $\mathrm{m} / \mathrm{z} 401$ (7), and $\mathrm{m} / \mathrm{z} 419$ (5 and 6). The peak at $3 \mathrm{~min}\left({ }^{*}\right)$ was unlikely sesterterpene derivative based on the TLC behavior

C2, C3, C7-trihydroxy derivatives. Detailed 2D NMR analyses enabled us to determine that both compounds had the same planar structure. In ${ }^{13} \mathrm{C}$ NMR spectra of these trihydroxy acids 5 and 6, apparent differences were only observed around C3. Notably, ${ }^{13} \mathrm{C}$ chemical shifts of the $\mathrm{C} 20$ methyl group showed clear differences $\left(\delta_{\mathrm{C}} 21.8\right.$ in $\mathbf{5}$ and $\delta_{\mathrm{C}} 28.2$ in $\left.\mathbf{6}\right)$, suggesting that $\mathbf{6}$ was a $\mathrm{C} 3$ epimer of $\mathbf{5}$. In NOESY spectra of $\mathbf{5}$ and $\mathbf{6}$, NOE correlations between $\mathrm{H} 2-\mathrm{H} 4 \alpha$ and $\mathrm{H} 4 \beta-\mathrm{H} 21$ were observed, suggesting that their stereochemistries were $2 R, 7 R$ (Figure $\mathrm{S} 3$ ). This observation was further supported by NOESY analyses; NOE between $\mathrm{H} 2$ and $\mathrm{H} 20$ was not observed for $\mathbf{5}$, while the corresponding NOE was observed for $\mathbf{6}$. To obtain the corresponding acetonides from $\mathbf{5}$ and $\mathbf{6}$, both compounds were treated with acetone in the presence of $p$-TsOH. Unexpectedly, both compounds gave the same acetonide 9 (Figure S5), which showed similar NOEs to those of $\mathbf{5}$, indicating its stereochemistry was $2 R, 3 R$ and thus the stereochemistry of $\mathbf{6}$ should be $2 R, 3 S$ (Figure S6).

Structures of the minor products $\mathbf{7}$ and $\mathbf{8}$ (betaestacin Vc and VI) were also determined in a similar way. Molecular formulae of 7 and 8 suggested that they may be dihydroxy and monohydroxy derivatives of 4. In the HMBC spectra of $\mathbf{7}$, correlations were observed between the exo-C20-methylene signals and the C2-oxymethine signal and between the C21methyl group and the C7-oxygenated carbon/C6-olefin carbon signals, suggesting a planar structure. In ${ }^{1} \mathrm{H}$ NMR of 8 broad singlet of $\mathrm{H} 10$ and olefinic proton of $\mathrm{H} 5$ were missing, while $\mathrm{C} 5$ oxymethine signal was observed at $4.37 \mathrm{ppm}$. This signal was correlated to $\mathrm{C} 3$ and $\mathrm{C} 7$-signals in $\mathrm{HMBC}$ spectra suggesting that $\mathbf{8}$ is a 5-hydroxy acid. In NOESY spectra of 7, NOE correlations between $\mathrm{H} 2-\mathrm{H} 4 \alpha$ and $\mathrm{H} 4 \beta-\mathrm{H} 21$ similar to those in $\mathbf{5}$ and $\mathbf{6}$ were observed, suggesting that its stereochemistry was $2 R, 7 R$ (Figure S3). In the NOESY spectra of $\mathbf{8}$, H5 showed NOEs between both $\mathrm{H} 22$ and $\mathrm{H} 20$, indicating that the stereochemistry of C5 was $S$ (Figure S3).

Structure determination of a series of betaestacin analogs enabled us to propose the biosynthetic pathway as shown in Scheme 2. $\mathrm{BtcB}_{\mathrm{Co}}$ oxidizes the $\mathrm{C} 25$ methyl group to yield the carboxylic acid 4 via the alcohol 3. On the other hand, $\mathrm{BtcB}_{\mathrm{Pb}}$ catalyzes another three-step oxidation to yield the diacid $\mathbf{2}$. The structure of the 5-hydroxy acid $\mathbf{8}$ suggested that an initial hydrogen abstraction catalyzed by $\mathrm{P} 450 \mathrm{BtcC}_{\mathrm{Co}}$ may occur at $\mathrm{C} 7$ and $\mathrm{C} 10$ to obtain a putative C7-hydroxy product $\mathbf{1 0}$ and a $\mathrm{C} 5$ hydroxy acid 8 rearranged at the $\mathrm{C}$ ring, respectively. In the case of the product $\mathbf{8}, \mathrm{BtcC}_{\mathrm{Co}}$ might not accept $\mathbf{8}$ with it being accumulated as a plausible shunt product. On the other hand, a C7-hydroxy acid $\mathbf{1 0}$ may be further converted to the putative epoxide 11. Considering the reactivity of the $\mathrm{C} 3$-alcohol in the acetonide formation of $\mathbf{5}$ and $\mathbf{6}$, non-enzymatic epoxide opening resulted in the formation of the carbocation $\mathbf{1 2}$ under acidic condition, which was quenched by either addition of water or H16 deprotonation to yield $\mathbf{5}-\mathbf{7}^{13}$. In the study of heterologous production of ophiobolin in solid medium, similar side reactions occurred to yield by-products. ${ }^{12}$ Although an $\mathrm{S}_{\mathrm{N}} 1$-type epoxide opening is rare, co-occurrence of epimeric chaetoglobosins $\mathrm{Q}$ and $\mathrm{R}$ might be explained by this mechanism ${ }^{14}$. Cationic epoxide rearrangements have also been reported recently in the biosynthesis of the alkaloid aspoquinolone ${ }^{15}$.

As various secondary metabolite gene clusters were expressed in the infection of Colletotrichum species ${ }^{16,17}$, we examined gene expression of the $b t c A_{C o}$ gene cluster in infection of Nicotiana benthamiana ${ }^{17}$. Although expression was highest in vitro-grown hyphae $(\mathrm{VH}), b t c A_{\mathrm{Co}}$ was also expressed in the early stages of the infection (1 dpi and 3 dpi) at lower levels (Figure S7A). This observation indicated that isolated betaestacins might have a physiological functions in this fungus. We then constructed the btc $A_{C o}$ disruptant of $C$. orbiculare to examine whether the mutant showed phenotypic changes. Two knockout mutants were successfully obtained by homologous recombination and disrupting the target gene with a hygromycin resistance gene cassette (HPT) (Figure S7B, C). Gene knock-out (KO) was confirmed by PCR. Two btcA $A_{C o}$ KO mutants, \#12 and \#46, showed normal growth and pigmentation on plate culture (Figure S7D). Conidial formation of each mutant was also examined on PDA plates. Each mutant produced conidia at a similar level to wild type $C$. orbiculare (Figure S7E). As knock-out mutants did not exhibit any phenotypic changes in vitro, the isolated metabolites may function by manipulating host plants. The infection process for this mutant is under investigation and will be reported elsewhere.

In summary, by functional characterization of two similar biosynthetic gene clusters in two phytopathogens we isolated seven previously unknown sesterterpenes. In this study, we found that two homologous $\mathrm{P} 450 \mathrm{~s}, \mathrm{BtcB}_{\mathrm{Pb}}$ and $\mathrm{BtcB}_{\mathrm{Co}}$, catalyzed multiple oxidations of isopropyl groups although the oxidation 

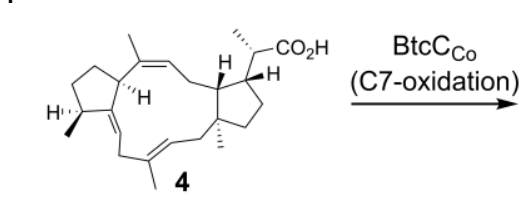

$\mathrm{BtcC}_{\mathrm{Co}}$ (C10-oxidation)
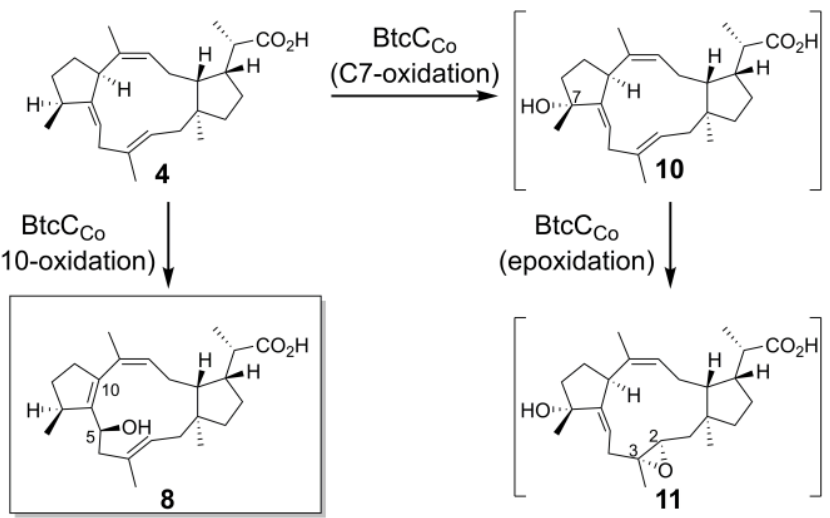

BtcC $_{\mathrm{Co}}$ (epoxidation)
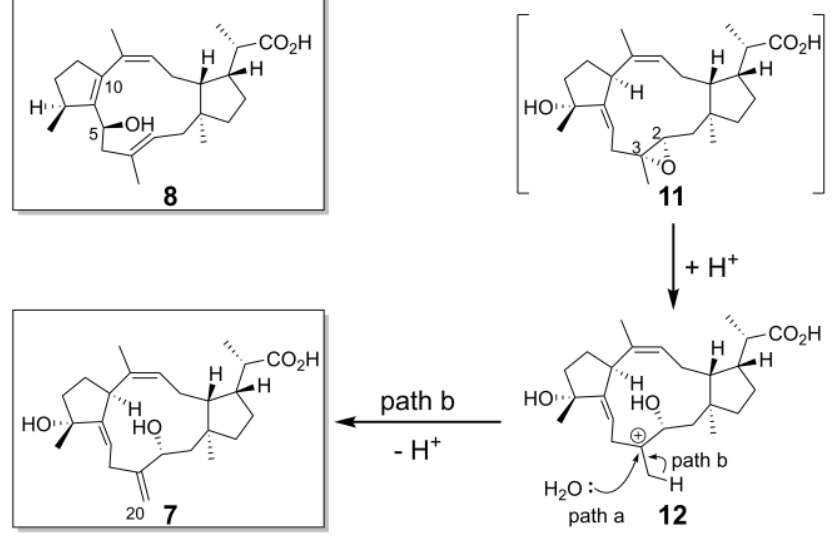

ath a 12

path a $\downarrow+\mathrm{H}_{2} \mathrm{O}$

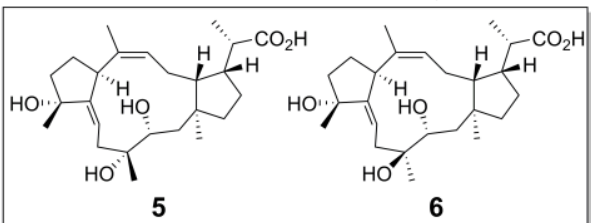

Scheme 2, Proposed mechanism for the biosynthesis of compounds $5-\mathbf{8}$.

levels were significantly different. The second set of homologous $\mathrm{P} 450 \mathrm{~s}, \mathrm{BtcC}_{\mathrm{Pb}}$ and $\mathrm{BtcC}_{\mathrm{Co}}$ showed a different behavior; $\mathrm{BtcC}_{\mathrm{Pb}}$ did not catalyze further oxidation while the corresponding $\mathrm{BtcC}_{\mathrm{Co}}$ did catalyze the multistep oxidation of 4 . Although the physiological functions of the identified metabolites remain to be elucidated, structural diversification of the same carbon skeleton by similar oxidation enzymes might be a strategy used by these phytopathogens for adaptation to the environmental changes in host plants.

\section{References and notes}

1. Toyomasu, T.; Tsukahara, M.; Kaneko, A.; Niida, R.; Mitsuhashi, W.; Dairi, T.; Kato, N.; Sassa, T. Proc. Natl. Acad. Sci. U. S. A 2007, 104, 3084-3088

2. Toyomasu, T.; Kaneko, A.; Tokiwano, T.; Kanno, Y.; Kanno, Y.; Niida, R.; Miura, S.; Nishioka, T.; Ikeda, C.; Mitsuhashi, W.; Dairi, T.; Kawano, T.; Oikawa, H.; Kato, N.; Sassa, T. J. Org. Chem. 2009, 74, 1541-1548.

3. Chiba, R.; Minami, A.; Gomi, K.; Oikawa, H. Org. Let. 2013, 15, 594-597.

4. Ye, Y.; Minami, A.; Mandi, A.; Liu, C.; Taniguchi, T.; Kuzuyama, T.; Monde, K.; Gomi, K.; Oikawa, H. J Am Chem Soc 2015, 137, 11846.

5. Qin, B.; Matsuda, Y.; Mori, T.; Okada, M.; Quan, Z. Y.; Mitsuhashi, T.; Wakimoto, T.; Abe, I. Angew.Chemi. Int. Ed. 2016 $55,1658-1661$.

6. Matsuda, Y.; Mitsuhashi, T.; Quan, Z. Y.; Abe, I. Org. Lett. 2015, 17, 4644-4647.

7. Okada, M.; Matsuda, Y.; Mitsuhashi, T.; Hoshino, S.; Mori, T.; Nakagawa, K.; Quan, Z. Y.; Qin, B.; Zhang, H. P.; Hayashi, F.; Kawaide, H.; Abe, I. J. Am. Chem. Soc. 2016, 138, 10011-10018.

8. Matsuda, Y.; Mitsuhashi, T.; Lee, S.; Hoshino, M.; Mori, T.; Okada, M.; Zhang, H. P.; Hayashi, F.; Fujita, M.; Abe, I. Angew. Chem. Int. Ed. 2016, 55, 5785-5788.

9. Bian, G. K.; Han, Y. C.; Hou, A. W.; Yuan, Y. J.; Liu, X. H.; Deng, Z. X.; Liu, T. G. Metab. Eng. 2017, 42, 1-8.
10. Mitsuhashi, T.; Rinkel, J.; Okada, M.; Abe, I.; Dickschat, J. S. Chem. Eur. J. 2017, 23, 10053-10057.

11. Narita, K.; Chiba, R.; Minami, A.; Kodama, M.; Fujii, I.; Gomi K.; Oikawa, H. Org. Lett. 2016, 18, 1980-1983.

12. Narita, K.; Sato, H.; Minami, A.; Kudo, K.; Gao, L.; Liu, C.; Ozaki, T.; Kodama, M.; Lei, X.; Taniguchi, T.; Monde, K.; Yamazaki, M.; Uchiyama, M.; Oikawa, H. Org. Lett. 2017, 19, 6696-6699.

13. When $\mathrm{C} 2 / \mathrm{C} 3$-vic-diol 5 was treated with $p$-TsOH in methanol, 1:2 epimeric mixture (ratio was roughly estimated by peak areas in chromatogram extracted at $210 \mathrm{~nm}$ ) of C3-methoxy derivatives were generated, suggesting that these mixtue were formed by $\mathrm{S}_{\mathrm{N}} 1$ type epoxide opening via the corresponding C3 carbocation intermediate 11

14. Jiao, W. X.; Feng, Y. J.; Blunt, J. W.; Cole, A. L. J.; Munro, M. H. G. J. Nat. Prod. 2004, 67, 1722-1725.

15. Zou, Y.; Garcia-Borras, M.; Tang, M. C.; Hirayama, Y.; Li, D. H.; Li, L.; Watanabe, K.; Houk, K. N.; Tang, Y. Nat. Chem. Biol. 2017, 13, 325-332.

16. O'Connell, R. J.; Thon, M. R.; Hacquard, S.; Amyotte, S. G.; Kleemann, J.; Torres, M. F.; Damm, U.; Buiate, E. A.; Epstein, L.; Alkan, N.; Altmuller, J.; Alvarado-Balderrama, L.; Bauser, C. A.; Becker, C.; Birren, B. W.; Chen, Z. H.; Choi, J.; Crouch, J. A.; Duvick, J. P.; Farman, M. A.; Gan, P.; Heiman, D.; Henrissat, B.; Howard, R. J.; Kabbage, M.; Koch, C.; Kracher, B.; Kubo, Y.; Law, A. D.; Lebrun, M. H.; Lee, Y. H.; Miyara, I.; Moore, N.; Neumann, U.; Nordstrom, K.; Panaccione, D. G.; Panstruga, R. Place, M.; Proctor, R. H.; Prusky, D.; Rech, G.; Reinhardt, R.; Rollins, J. A.; Rounsley, S.; Schardl, C. L.; Schwartz, D. C.; Shenoy, N.; Shirasu, K.; Sikhakolli, U. R.; Stuber, K.; Sukno, S A.; Sweigard, J. A.; Takano, Y.; Takahara, H.; Trail, F.; van der Does, H. C.; Voll, L. M.; Will, I.; Young, S.; Zeng, Q. D.; Zhang, J. Z.; Zhou, S. G.; Dickman, M. B.; Schulze-Lefert, P.; van Themaat, E. V. L.; Ma, L. J.; Vaillancourt, L. J. Nat. Genet. 2012 44, 1060-1065.

17. Gan, P.; Ikeda, K.; Irieda, H.; Narusaka, M.; O'Connell, R. J.; Narusaka, Y.; Takano, Y.; Kubo, Y.; Shirasu, K. New Phytol. 2013, 197, 1236-1249.

\section{Acknowledgements}

This work was financially supported by Grants-in-Aid for Scientific Research from the Ministry of Education, Culture, Sports, Science and Technology, Japan (JSPS KAKENHI Grants (15H01835 (H.O.), 16H06446 (A.M.), 17H05425 (T.O.).) and partly supported by the JSPS A3 Foresight Program. The work in Shirasu lab is supported in part by KAKENHI $17 \mathrm{H} 06172$.

\section{Supplementary Material}

Supplementary data (experimental procedures, supplementary figures and tables, and NMR data) associated with this article can be found in the online version. 